\title{
Identification of the 4-Hydroxycinnamate Decarboxylase (PAD) Gene of Klebsiella oxytoca
}

\author{
Hirofumi UchiYama, Yasuyuki Hashidoko, ${ }^{\dagger}$ Yuhki KuriYama, and Satoshi Tahara \\ Division of Applied Bioscience, Research Faculty of Agriculture, Hokkaido University, \\ Kita-ku, Sapporo 060-8589, Japan
}

Received August 3, 2007; Accepted October 15, 2007; Online Publication, January 7, 2008

[doi:10.1271/bbb.70496]

\begin{abstract}
A 7.1-kbp DNA fragment isolated from a wild strain of Klebsiella oxytoca was sequenced, leading to the identification of 10 open-reading frames (ORFs), including a 504-bp Pad gene. The Pad gene of the Gramnegative bacterium was subsequently expressed in Escherichia coli as a chimeric Pad. The deduced amino acid (AA) sequence of the Pad gene from wild-type K. oxytoca showed approximately $50 \%$ homology to those of other bacterial PADs from Gram-positive bacilli plus a coccus. These data and a genomic library search of some $\gamma$-proteobacteria, including $E$. coli and Vibrio sp., indicated that PAD of $K$. oxytoca is a member of the bacterial PAD family characteristic of Gramnegative bacteria. Using Pad-specific PCR primers designed from the Gram-negative bacterial Pad of $K$. oxytoca, Pad genes of two further strains of $K$. oxytoca, another wild isolate and JCM 1665 and two PADpositive Enterobacter spp. were successfully amplified for specific Pad detection.
\end{abstract}

Key words: Klebsiella oxytoca; bacterial Pad gene; PCR detection of Pad; Gram-negative bacteria; 4-hydroxycinnamate decarboxylase gene

Some plant families, such as Convolvulaceae, Asteriaceae, and Umbelliferae, are representative chlorogenic acid-accumulating plant families that contain high concentrations of hydroxycinnamoyl quinic acids in their leaves and/or roots. Many of these plant polyphenols are now recognized as self-defensive substances, but the roles of these plant products in interactions between polyphenol-rich plants and host-associating microorganisms are not well understood. ${ }^{1,2)}$ In 1993, Hashidoko et al. investigated phylloplane bacteria from the chlorogenic acid-accumulating plant Polymnia sonchifolia, a member of the Asteriaceae family. A phylloplane bacterium was tentatively identified as Klebsiella oxytoca by morphological and biochemical characterization. This organism was found actively to decarboxylate 4-hydroxylated cinnamic acids by a substrateinducible 4-hydroxycinnamate decarboxylase (4-HCD; also a synonym of phenylacrylic acid decarboxylase, PAD) to utilize the decarboxylative product, 4-hydroxylated styrene, as an antifungal agent. ${ }^{3)}$ In 1994, Hashidoko et al. successfully cloned the Pad gene from a genomic library prepared from wild-type $K$. oxytoca. ${ }^{4)} \mathrm{A}$ 9.6-kbp genomic fragment carrying the Pad gene was obtained using Cladosporium herbarum AHU 9262 as a bioindicator which was highly sensitive to 4-hydroxystyrene produced from 4-hydroxycinnamic acid via PAD catalytic decarboxylation. Transformed Escherichia coli JM 109 harboring the cloned Pad gene region acquired the ability to decarboxylate $(E)$-4-hydroxycinnamate into 4-hydroxystyrene. Digestion with $\mathrm{SacI}$ and EcoRI cleaved this 9.6-kbp DNA region into three fragments: HindIII-EcoRI (2.4 kbp, fragment C), EcoRISacI (4.7 kbp, fragment B), and SacI-HindIII (2.5 kbp, fragment A). These three fragments were independently cloned into the pUC19 vector. The expression of $\mathrm{Pad}$ in each fragment in transformed $E$. coli was unsuccessful. Only bacterial cells transformed with recombinant DNA containing fragment CB (7.1 kbp, HindIII-SacI possessing an EcoRI site inside the DNA sequence) gained the ability to decarboxylate 4-hydroxycinnamic acid (unpublished data), but the DNA sequence of the Pad gene on fragment $\mathrm{CB}$ has not yet been characterized.

Bacterial Pad gene studies have been done in food chemistry, due to serious issues of off-flavor during the fermentation of foods and liquor. In 1995, bacterial Pad of Gram-positive Bacillus pumilis was first characterized by Zago et al., and a full-length amino acid (AA) sequence of PAD was deduced. ${ }^{5)}$ Since this identification of Pad, additional Pad genes have been characterized in more than 20 different microorganisms, but almost all of these microorganisms are Gram-positive bacilli plus a coccus. ${ }^{6-8)}$ In contrast, among Gramnegative bacteria, only Pseudomonas fluorescens ${ }^{9)}$ and $K$. oxytoca ${ }^{10)}$ have been reported to possess PAD activity in crude protein from bacterial cells. Bacterial Pad-like ORFs have been found in genomic DNA from two Gram-negative proteobacteria, Vibrio cholerae and Erwinia carotovora, ${ }^{11,12)}$ but it is uncertain whether the

\footnotetext{
$\dagger$ To whom correspondence should be addressed. Fax: +81-11-706-4182; E-mail: yasu-h@abs.agr.hokudai.ac.jp
} 
encoded gene products possess PAD functionality in vivo. Hence both the enzymatic and the bacteriophysiological traits of PAD have yet to be examined in Gram-negative bacteria. In fact, the physiological and ecological roles of PAD-producing bacteria and PAD itself in the terrestrial ecosystem are unclear, because $K$. oxytoca immediately hydrolyzed chlorogenic acid to yield 4-hydroxylated styrenes in chlorogenic acid-containing potato-dextrose medium. ${ }^{13)}$ In this study, we aimed to determine the DNA sequence of Pad in fragment $\mathrm{CB}$ originating in epiphytic $K$. oxytoca, and to describe the PADs of other strains of $K$. oxytoca and two further wild isolates of Enterobacter spp.

\section{Materials and Methods}

General. The 7.1-kb DNA fragment (fragment CB) carrying the gene for PAD was identical to one previously cloned from chromosomal DNA of a wildtype $K$. oxytoca bacterial strain. This DNA fragment possessed HindIII and SacI sites at the $5^{\prime}$ and $3^{\prime}$ ends respectively, and it was cloned into pUC19 vector plasmid. For PCR, HotStarTaq (Qiagen, Germantown, MD) was used at $97^{\circ} \mathrm{C}$ for $15 \mathrm{~min}$ for preliminary heating. The reaction conditions are described in detail for each experiment below. DNA and amino acid (AA) sequence homology searches were performed on the website of NCBI (National Center for Biotechnology Information, USA) and DDBJ (DNA Data Bank of Japan, Mishima, Japan).

Primer design for direct sequencing. The primers used in this study are shown in Table 1 . Based upon the sequence determination obtained from the initial round of sequencing, we designed customized forward/reverse internal primers. The DNA sequence of fragment $\mathrm{CB}$ was registered in the DDBJ DNA data bank under accession no. AB330293.

Table 1. Primers Used in Sequencing of Fragment CB

\begin{tabular}{ll}
\hline \hline 5'-GTTCCACGGTCTCTTCC-3' & $(160-176)$ \\
5'-GATGTTGATGATCTGCC-3' & $(395-411)$ \\
5'-GGATAATCTTCAGGTTCTC-3' & $(837-856)$ \\
5'-GTTTCGCTTTCACCGT-3' & $(1,707-1,722)$ \\
5'-ATGTCATCGCACAGCA-3' & $(1,815-1,830)$ \\
5'-CATCCCGACGAACTGG-3' & $(2,208-2,221)$ \\
5'-AGAGCGATGACGCTGCCGAA-3' & $(2,336-2,355)$ \\
5'-GGATCTCAACCG-3' & $(2,474-2,486)$ \\
5'-GTTGATCATCTTCGAGG-3' & $(2,635-2,651)$ \\
5'-GCTTCGGTGAGCAT-3' & $(2,888-2,901)$ \\
5'-GAGTCATCGCTGCT-3' & $(2,909-2,922)$ \\
5'-AGCTCGCGCAGATAG-3' & $(3,399-3,413)$ \\
5'-GGATAATTGCTTTGGTTC-3' & $(3,832-3,849)$ \\
5'-CGTGAAACAGTTTATCG-3' & $(4,843-4,859)$ \\
5'-GTCGGTGAGCTATAATCTC-3' & $(5,412-5,430)$ \\
5'-ATGCGGTGCTGTATCAG-3' & $(5,974-5,990)$ \\
5'-CGCCGAATGATATCAC-3' & $(6,418-6,433)$ \\
5'-GCTCCGTCGCAGTTCAAAGA-3' & $(6,840-6,859)$ \\
5'-ATGGGTACTGAAGG-3' & $(6,905-6,918)$ \\
\hline
\end{tabular}

Characterization of ORF regions in fragment $C B$. The target DNA (fragment CB), possessing 7,102 bp between the HindIII and SacI sites, did not contain any regions that exhibited high homology to Pad of Bacillus spp. Hence all of the ORF regions on this DNA fragment were searched by means of an ORF Finder tool provided by NCBI (http://www.ddbj.nig.ac.jp/search/blast-j.html). ORF regions were searched from both plus and minus strand directions with putative amino acid translations from three different frames $(+1,+2,+3,-1,-2$, and $-3)$. A total of $20 \mathrm{ORF}$ candidates of $250 \mathrm{bp}$ or greater were identified on the target DNA. The deduced amino acid (AA) sequences of the putative proteins encoded on each ORF were further searched on the BLASTX database of DDBJ (http://www.ddbj.nig.ac.jp/search/ blast-j.html).

Design of adapter primers for Pad gene insertion into $p G E X$ 4T-3. In order to sub-clone target ORF regions into the pGEX vector, adapter primers were designed on the SIGMA Genosys website (http://www.genosys.jp/adt/ SGJ_NN_3rd.html), and predictions for Tm, hairpin, and dimer structures were obtained. The designed adapter primers were: PAD-APF (forward, 5'-CGGAATTCTATGAGCACATTCGACAAACA-3', 29 mer, $T m=$ $73^{\circ} \mathrm{C}$ ), and PAD-APR (reverse, 5'-CGCTCGAGGATTACAGGTTGGCAGGAA-3', $27 \mathrm{mer}, \quad T m=77^{\circ} \mathrm{C}$ ). These primers possessed EcoRI and XhoI restriction sites at the $5^{\prime}$ and $3^{\prime}$ ends respectively. The specificity of the primers was confirmed by PCR using fragment CB as the source of template DNA. PCR conditions were as follows for the amplification of the ORF-7 regions: 30 cycles of denaturation at $94{ }^{\circ} \mathrm{C}$ for $1 \mathrm{~min}$, annealing at $50{ }^{\circ} \mathrm{C}$ for $1 \mathrm{~min}$, and extension at $72^{\circ} \mathrm{C}$ for $1 \mathrm{~min}$.

The resulting $\mathrm{PCR}$ product $(523 \mathrm{bp})$ was doubledigested with EcoRI and XhoI, and the enzymes were denatured by heating. The digested PCR product was then ligated into pGEX 4T-3 expression vector (Amersham Pharmacia Biotech, Uppsala, Sweden) at the EcoRI-XhoI cloning site for in-frame fusion to the internal GST gene in pGEX 4T-3. A set of adapter primers ( -1 , AP3, and AP4) was designed for Pad expression. The ligation reaction was set at a molar ratio of the vector plasmid:PCR product $=1: 10$. E. coli cells were transformed with the recombinant plasmid to facilitate the production of recombinant, PAD GSTfusion protein. Transformed cells were assayed for PAD activity with a decarboxylation test in the cultured medium using $(E)$-caffeic acid as the substrate. ${ }^{10)}$

Confirmation of PAD activity in E. coli transformed with recombinant pGEX 4T-3 plasmid. E. coli JM109 competent cells (Nippon Gene, Toyama, Japan) were transformed with the recombinant pGEX 4T-3PAD plasmid carrying the Pad gene. Hundreds of colonies emerged on a selection plate containing $50 \mathrm{mg} /$ liter of ampicillin. Among these, 96 colonies (B1-B96) were taken randomly from the selection plates and subjected 
Table 2. ORFs on Fragment CB

\begin{tabular}{|c|c|c|c|c|}
\hline no & Frame & Position & Size & Protein \\
\hline 1 & -1 & $2083-98$ & 1986 & NAD-dependent epimerase/dehydratase, formyl transferase \\
\hline 2 & -1 & $4315-3065$ & 1251 & UDP-4-amino-4-deoxy-L-arabinose oxoglutarate aminotransferase \\
\hline 3 & +2 & $152-1264$ & 1113 & Not hit \\
\hline 4 & -2 & $3117-2080$ & 1038 & Glycosyl transferase \\
\hline 5 & +2 & $6248-7102$ & 855 & Bacterial extracellular solute-binding protein \\
\hline 6 & +1 & 2530-3099 & 570 & Carboxyl esterase (Burkholderia sp.) \\
\hline 7 & -1 & $5107-4604$ & 504 & Bacterial phenolic acid decarboxylase $(\mathrm{Pad})$ \\
\hline 8 & +2 & $3221-3676$ & 456 & Not hit \\
\hline 9 & +2 & $5645-6067$ & 423 & Transcriptional regulator LysR family \\
\hline 10 & -2 & $1665-1251$ & 405 & Not hit \\
\hline 11 & +2 & $2171-2569$ & 399 & Not hit \\
\hline 12 & +3 & $5208-5588$ & 381 & Transcriptional regulator LysR family \\
\hline 13 & -1 & $6658-6278$ & 381 & GTP binding protein (only for domain near N-terminal) \\
\hline 14 & +2 & $4769-5131$ & 363 & Not hit \\
\hline 15 & +2 & $1772-2101$ & 330 & Not hit \\
\hline 16 & +3 & $1545-1835$ & 291 & Not hit \\
\hline 17 & -1 & $7102-6815$ & 288 & Ni-binding periplasmic protein \\
\hline 18 & +1 & 79-363 & 285 & Not hit \\
\hline 19 & +3 & $771-1055$ & 285 & Not hit \\
\hline 20 & +3 & $390-656$ & 267 & Not hit \\
\hline
\end{tabular}

All of the ORFs greater than $250 \mathrm{bp}$ are listed. ORF-7 encoded a putative protein that showed high sequence homology to bacterial PADs of Gram-positive bacteria.

to an insert check. Positive clones were then tested for decarboxylation activity. In this assay, $(E)$-caffeic acid was added as the substrate of PAD to 12-h-cultured medium to obtain a final concentration of $1 \mathrm{mM}$. After further incubation for $30 \mathrm{~min}$, the medium was extracted with EtOAc, concentrated, and developed on TLC (Merck Kieselgel $\mathrm{F}_{254}$ Art 5715, 0.25 mm thick, Merck, Darmstadt, Germany) in $\mathrm{CHCl}_{3}-\mathrm{MeOH}=9: 1$ to check for the presence of 3,4-dihydroxystyrene.

Recovery of the Pad gene fragment from the PAD positive clone. The PAD assay-positive clones were cultured in LB-ampicillin medium for $24 \mathrm{~h}$ at $37^{\circ} \mathrm{C}$. The recombinant plasmid copied was recovered from the cultured $E$. coli cells by the lysozyme-alkaline method. The resulting plasmid was subjected to double-digestion with EcoRI/XhoI to obtain about $500 \mathrm{bp}$ of inserted DNA. This fragment was subsequently sequenced (ABI PRISM $^{\mathrm{TM}} 310$ Genetic Analyzer, Applied Biosystems, Foster City, CA) in order to confirm the amplified DNA to be Pad from ORF-7.

Design of degenerate PCR primers for reliable Pad gene detection by PCR. The characterized Pad gene of $K$. oxytoca possessed some common motifs with those of Bacillus spp., ${ }^{5,7)}$ Lactobacillus spp., ${ }^{6)}$ and Pediococcus pentosaceus. ${ }^{8)}$ Bacterial Pad gene-detecting primers were designed from common motifs common to these organisms. The degenerate primers were then tested on Gram-negative bacteria isolated from the rhizosphere of wild plants collected throughout the Hokkaido University Campus. ${ }^{14)}$ Together with $K$. oxytoca JCM 1665, used as a reference bacterium, ${ }^{13)}$ these five newly isolated bacteria were tested for PCR detection of bacterial Pads. These were tentatively identified as
K. oxytoca 60E, two Enterobacter spp. (70S and 136A), and two Burkholderia spp. (67A and 67R). Among the tested Gram-negative bacteria, K. oxytoca JCM 1665, and $K$. oxytoca $60 \mathrm{E}$ possessed a substrate-dependent, inducible type of PADs. On the other hand, Enterobacter spp. 70S and 136A possessed a constitutive type of PAD, the latter of which was relatively weak in decarboxylation activity. Burkholderia spp. showed no PAD activity even in the presence of substrates, but they showed remarkable gallate decarboxylation activity equal to Rhanella aquatilis. ${ }^{15)} \mathrm{K}$. oxytoca $60 \mathrm{E}$, Enterobacter sp. 70S, and Enterobacter sp. 136A were originally isolated from the roots of Chenopodium album, Rudbeckia laciniata, and C. album respectively. Two Burkholderia spp., 67A and 67R, were from a Polygonum sp.

\section{Results}

Identification of bacterial Pad from Klebsiella oxytoca

Full DNA sequencing of fragment CB $(7.1 \mathrm{~kb}$, HindIII-SacI fragment from wild-type $K$. oxytoca) resulted in the identification 20 open reading frames (ORFs, ORF-1-20) that were greater than $250 \mathrm{bp}$ in size. Among these, 11 ORFs encoded proteins/enzymes of known function (Table 2). Partial N-terminal amino acid (AA) sequences of ferulic acid decarboxylases purified from L. plantarum and Pseudomonas fluorescens ${ }^{16,17)}$ exhibited 50\% homology to the AA sequence encoded in ORF-7 (5,107-4,604, on the reverse chain). The putative amino acid sequence encoded in ORF-7 was searched on InterProScan (http://www.ebi.ac.uk/InterProScan/). ${ }^{18)}$ The 504 bases of ORF-7 were characterized as the Pad gene in view of nearly $50 \%$ agreement of the coding 
B

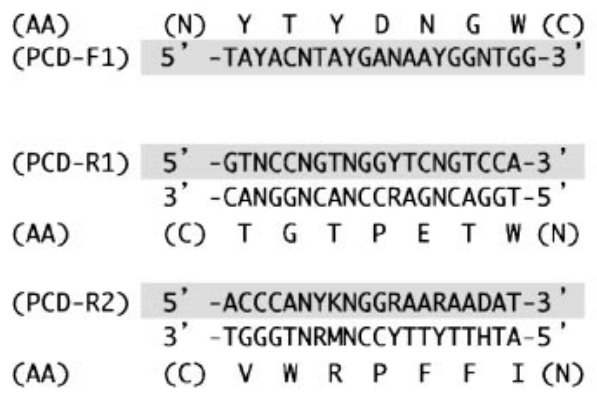

C

PAD-1F/PAD-1R

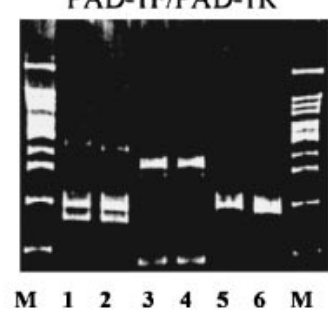

PAD-1F/PAD-2R

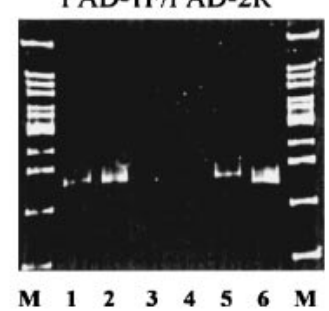

Fig. 1. Differences in PAD Characters between Gram-Positive Bacilli and Gram-Negative Rods.

A, The AA motifs indicated by colored backgrounds are preserved AA sequences among bacterial PADs. Using three motifs out of four, degenerate primers were designed for bacterial Pad-detecting PCR. KO, Klebsiella oxytoca; PP, Pediococcus pentosaceus; LP, Lactobacillus plantarum; BS, Bacillus subtilis; BP, Bacillus pumilus. *, identical amino acids. B, Oligonucleotide sequences of degenerate primers for bacterial PADs to cover Gram-negative bacteria. C, Bacterial PAD-detecting PCR assay for some test bacteria. Left, PCR products with PCDF1/PCDR1; right, PCR products with PCD-F1/PCD-R2 primers. Electrophoresis was performed in a $4 \%$ stacking and $13 \%$ separating polyacrylamide gel. M, marker is a 100-bp ladder marker (100-1,000 and 1,500); 1, Klebsiella oxytoca 60E; 2, K. oxytoca JCM 1665; 3 , Burkholderia sp. 67A; 4, Burkholderia sp. 67R; 5, Enterobacter sp. 70S; and 6, Enterobacter sp. 136A. Both PCR detections, with PAD-F1/ PAD-R1 and PAD-F1/PAD-R2, were performed under the following PCR conditions: 35 cycles of denaturation at $94^{\circ} \mathrm{C}$ for 1 min, annealing at $50^{\circ} \mathrm{C}$ for $1 \mathrm{~min}$, and extension at $72^{\circ} \mathrm{C}$ for $1 \mathrm{~min}$. The volume of each primer solution $(50 \mu \mathrm{M})$ added to the reaction solution $(50 \mu \mathrm{l})$ was $1.5 \mu \mathrm{l}$. The resulting PCR products were run on a 13\% polyacrylamide gel by slab gel electrophoresis along with a 100-bp ladder marker.

AA sequences with PADs reported from Gram-positive bacilli and a coccus. Furthermore, some conserved motifs common to PAD family proteins were identified in the PAD gene (Fig. 1A). ${ }^{5-8)}$

After full sequencing of fragment $\mathrm{CB}$, it was evident that ORF-7 was located in reverse orientation to the lac promoter in the pUC19 plasmid. In addition, the sole EcoRI site was located at positions, 2,449-2,454, a region that was a long distance from ORF-7. Since neither fragment $\mathrm{C}$ nor $\mathrm{B}$ showed PAD activity on each recombinant plasmid when fragment $\mathrm{CB}$ was digested with EcoRI, we expected that the Pad gene would contain the EcoRI site, but this EcoRI site was not related to $\mathrm{Pad}$ gene expression. It is perplexing that the pUC plasmid carrying fragment $\mathrm{C}$ did not allow for the expression of PAD in transformed E. coli. On the other hand, it is reasonable in view of the reverse direction of the Pad gene against the lac promoter that IPTG failed to activate $P a d$ expression in cells transformed with the recombinant pUC19-CB-carrying Pad gene.

Since we failed to observe induction in the pUC19 system, we inserted the ORF-7 region into the pGEX4T-3 expression vector to obtain 10 independent colonies. The two clones (B35 and B43) tested were positive on caffeic acid decarboxylation assay (Fig. 2). The transformed $E$. coli JM109/pGEX-4T-3-PAD clone B43 was more active than pUC19-CB-transformed E. coli JM109. B35 and B43, selected as PAD-positive clones, were subsequently confirmed by PCR to carry the $\mathrm{Pad}$ gene in pGEX-4T-3-PAD plasmid. Expression of the Pad gene from Gram-positive bacteria in E. coli has been reported, ${ }^{19)}$ but this is probably the first example of gene expression of a Gram-negative bacterial Pad in E. coli.

Degenerate PCR for detection of the Pad gene using newly designed Pad-specific primers

The amino acid sequence of the characterized PAD of wild-type $K$. oxytoca indicated that it is a decarboxylase of the bacterial PAD family. Sequence analysis also confirmed the presence of some motifs common to those of Bacillus spp. and Lactobacillus plantarum. ${ }^{6}$ ) For the characterization of PADs possessing motifs similar to those of Gram-positive bacilli, detection of Pad in wildtype $K$. oxytoca and $K$. oxytoca JCM 1665 by DNA homology searches failed. Furthermore, PCR detection with degenerate primers designed from Gram-positive bacilli were unsuccessful (data not shown) until the ORF 


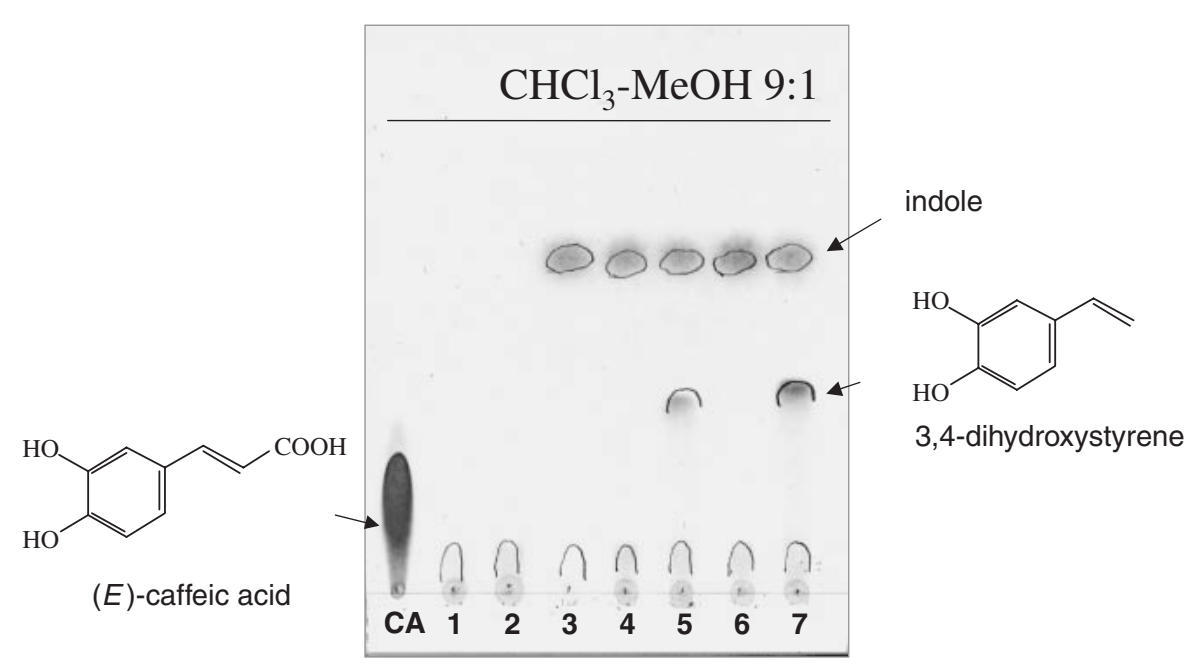

Fig. 2. PAD Activity of Transformed E. coli with the Pad Gene.

E. coli JM 109 that possessed ORF-7 inserted into pGEX-4T-3 expression vector plasmid (pGEX-4T-3-PAD). CA, caffeic acid only (5 mM in $10 \mathrm{ml}$ of water); 1 , LB broth medium only $(10 \mathrm{ml}) ; 2$, LB medium + caffeic acid; 3, E. coli JM109/pUC19 + IPTG and caffeic acid; 4, E. coli JM109/pGEX-4T-3 + IPTG and caffeic acid; 5, E. coli JM109/pUC19-CB + IPTG and caffeic acid (positive control); 6, E. coli JM109/pGEX-4T-3-PAD B40 + IPTG and caffeic acid (negative control); 7, E. coli JM109/pGEX-4T-3-PAD B43 + IPTG and caffeic acid (positive). In all portions, IPTG was added to the cultures from the initiation of incubation. After overnight culture, $5 \mathrm{~mm}$ of caffeic acid was added as the decarboxylation substrate, and these transformed $E$. coli were further incubated for $30 \mathrm{~min}$. After adjusting to $\mathrm{pH} 4.0 \mathrm{with} 1 \mathrm{M} \mathrm{HCl}$, $2 \mathrm{ml}$ of EtOAc was added to the medium, and the test tube was vortexed for $1 \mathrm{~min}$. The resulting EtOAc layer was then analyzed by TLC developed in $\mathrm{CHCl}_{3}-\mathrm{MeOH}$ 9:1.

search in fragment CB. Hence, we designed new degenerate primers from common motifs of AA sequences that are encoded on bacterial Pad genes and Pad-like pseudo-genes.

Based on comparisons among AA sequences of some bacterial PADs, including that of phytoepiphytic $K$. oxytoca and ones obtained in a database search, YTYDNGW (19-25 AA, for forward primer), WTEPTGT (70-76 AA, for 1st reverse), and IFFPRWV (93-99 AA, for 2nd reverse) were selected as the target motifs in the wild-type $K$. oxytoca PAD to design Pad-specific primers (Fig. 1A). In this primer design, YTYDNQW and IYFPRWI of Vibrio cholerae (AE004296) PAD, located at 19-25 AA and 93-99 AA respectively, ${ }^{12)}$ and YTYANGW and IFFPQWI of Mycobacterium avium subsp. paratuberculosis (AE017229) at 28-34 AA and 102-108 AA respectively ${ }^{20)}$ were not included. These regions were excluded because these bacteria were assumed to be neither soil nor plant-associating bacteria.

From the preserved AA motifs of the target PAD, a degenerate forward (PAD-F1, 5'-TAYACNTAYGANAAYGGNTGG-3') and two reverse (PAD-R1, 5'-GTNCCNGTNGGYTCNGTCCA-3' and PAD-R2, 5'-ACCCANYKNGGRAARAADAT-3') primers encoding the AA motifs were designed (Fig. 1B). Many of the PADpositive bacteria isolated from the rhizoplanes of several plants in our systematic screening in the field showed decarboxylation activities almost equivalent to a reference strain, $K$. oxytoca JCM 1665. Five wild strains of Gram-negative eubacteria, isolated from the root surfaces of various host plants, were subjected to PCR assay using these degenerate primers for Gram-negative bacterial Pad gene detection. Using the fragment $\mathrm{CB}$ as a positive control, the combination of PAD-1F/PAD-1R and $\mathrm{PAD}-1 \mathrm{~F} / \mathrm{PAD}-2 \mathrm{R}$ produced amplified $\mathrm{PCR}$ products of $172 \mathrm{bp}$ and $242 \mathrm{bp}$ respectively.

Consequently, two K. oxytoca and two Enterobacter spp. tested by PCR with the combination PAD-1F/PAD$1 \mathrm{R}$ produced products of reasonable fragment sizes ( $>200 \mathrm{bp}$ ), but the PCR products of two Burkholderia spp. were $300 \mathrm{bp}$ in size (Fig. 1C, left). On the other hand, while four $\gamma$-proteobacteria of K. oxytoca (JCM 1665 and 60E) and Enterobacter spp. (70S and 136A) tested positive on PCR assay with PAD-1F/PAD-2R, two Burkholderia spp. were negative (Fig. 1C, right). The PCR products obtained by PAD-1F/PAD-2R primers were sequenced and compared for homology to their respective PADs on the amino acid level (Fig. 3). The PCR products of $K$. oxytoca JCM 1665 and $60 \mathrm{E}$, both of which possessed an inducible type of active PADs, and Enterobacter sp. 70S with a constitutive PAD exhibited high homology to the partial AA sequence of bacterial PAD that was coded on the fragment CB from the phylloplane $K$. oxytoca. In contrast, Enterobacter sp. 136A, which possesses the constitutive type of PAD, exhibited low AA sequence homology to that of the inducible-type of Gram-negative bacteria.

Altogether, our degenerate primers, designed specifically for bacterial PAD gene detection, were applicable to $\gamma$-proteobacteria (genera Klebsiella and Enterobacter), but it is necessary to determine whether these primers are specific only to bacterial Pad of $\gamma$-proteobacteria (consisting mainly of inducible types of the PAD group), or whether they have broad specificity to 

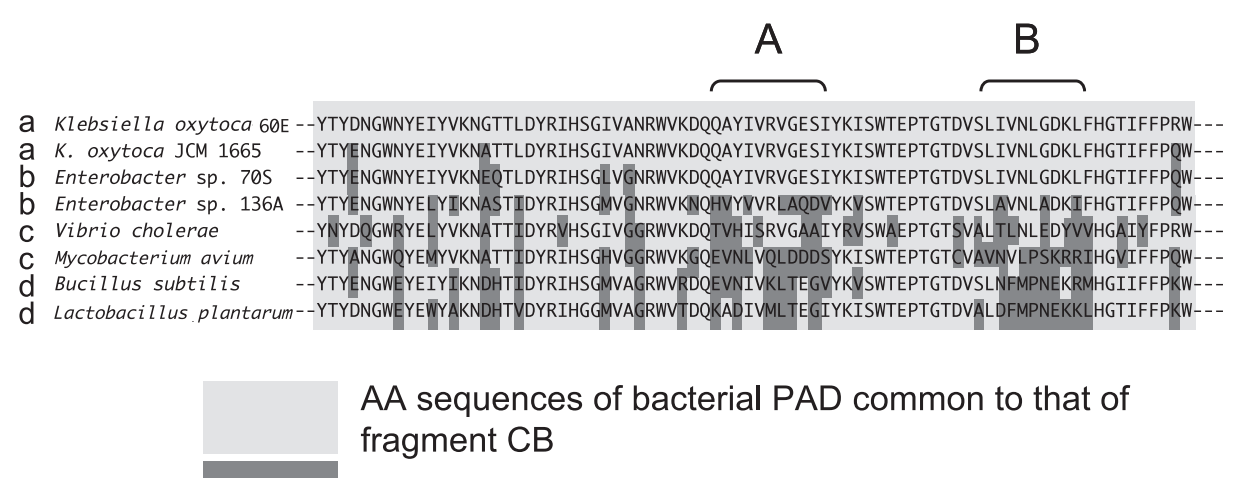

Alternative AA

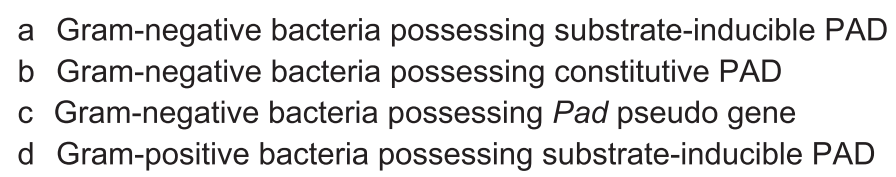

Fig. 3. Encoding Partial AA Sequences of the PCR Products from Bacterial Pad.

AA sequences shown by a light-gray background were common AA with substrate-inducible PADs of $K$. oxytoca, a Gram-positive bacterium. AA sequences alternative to those of $K$. oxytoca are shown by a dark-gray background, in which AA sequence variations were confirmed among Gram-positive bacteria and constitutive PADs or pseudo-gene-like Pad-possessing Gram-negative bacteria.

several bacterial genera and subclasses. In the PCR assay and subsequent DNA sequence determination, a constitutive type of bacterial PAD of Enterobacter sp. 136A was found to possess a unique AA sequence region. In other words, substrate-inducible PADs of $\gamma$ proteobacteria, at least, possess common motifs (the A and $\mathrm{B}$ regions as shown in Fig. 3). Because many of the constitutive types of PAD-possessing Gram-negative bacteria have been isolated (data not shown), it is necessary to determine whether constitutive PAD is separated into sub-families of PAD among Gramnegative bacteria. In our bacterial collection, they showed a diverse and wide range of variations of enzymatic behaviors of PADs. ${ }^{13,21)}$ A different group of PADs has been reported in ferulate decarboxylases of yeast (named yeast PAD1). Since this group of $\mathrm{Pad}$ genes do not exhibit any AA sequence homology to the bacterial PADs, ${ }^{22,23)}$ it is speculated that the origins of the yeast and the bacterial Pad genes are completely different. In fact, a function-unknown UbiX-like decarboxylase (PAD1) of Escherichia coli O157:H7 possesses an AA sequence that is highly homologous to those of yeast PAD1, ${ }^{24)}$ but $E$. coli does not show any PAD-like activity that is either constitutive or inducible.

\section{Discussion}

PADs produced by Gram-negative bacteria are grouped into two types: inducible PADs and constitutive PADs. ${ }^{21)}$ In our investigations, bacteria possessing constitutive PADs tended to be weakly active, and conversively, bacteria that contain substrate-inducible PADs were highly active on decarboxylation assay (data not shown), but it is not clear why some bacteria are capable of inducing PADs under exposure to substrates, or why it is necessary to accumulate such decarboxylative products in their habitat. Probably, de novo synthesis in PAD production is a trade-off between detoxification and energy consumption.

In our current research, $\mathrm{Pad}$ characterization from $K$. oxytoca, a Gram-negative phytoepiphyte (phylloplane bacterium) of $\gamma$-proteobacteria was done first, along with sequence determination of the upstream and downstream regions of the Pad gene. This is significant, because it will be possible to focus on important DNA regions associated with the regulation mechanism of substrate-dependent, inducible Pad gene expression in $K$. oxytoca. Since substrate-specificity and substratedependent induction of PAD has been well studied in $K$. oxytoca JCM 1665, genetic information from fragment BC is probably applicable to JCM 1665. In fact, it has been found that an indigested substrate analog, 6hydroxynaphthoic acid, acts in K. oxytoca JCM 1665 cells as a powerful PAD inducer, maintaining its induction activity longer than $(E)$-caffeic acid or other natural substrates. Thus, both chemical and genetic tools for further biochemical study became available. Barthelmebs et al. have reported as a pioneer work that PadA gene expression in Pediococcus pentosaceus is regulated by bicistronic transcription of a $P a d R$ gene located downstream of PadA. In this bacterium, the PadR protein acts as a transcriptional repressor of the PadA operon upstream of the PadA gene. It is important to note that similar repressor regions were not found upstream or downstream of ORF-7 in fragment BC. ${ }^{8)}$

The Pad gene-specific primers that were developed in this study should serve as a useful Pad-detection tool also for study of the environmental roles of the PAD- 
producing bacteria. Pad gene distribution and expression in phenolic compound-accumulated habitats of phytoepiphytic bacteria indicate the importance of the $\mathrm{PAD}$ reaction in the terrestrial ecosystem.

\section{Acknowledgments}

We thank Mr. Albert Asante of our laboratory for providing some of his rhizobacterial collections. This research was supported by a Grant-in-Aid for Scientific Research from JSPS (The Japan Society for the Promotion of Science) (no. 16208032, to Y.H.).

\section{References}

1) Kosuge, T., The role of phenolics in host response to infection. Annu. Rev. Phytopathol., 7, 195-222 (1969).

2) Friend, J., Phenolic substances and plant disease. Annu. Proc. Phytochem. Soc., 25, 367-372 (1985).

3) Hashidoko, Y., Urashima, M., Yoshida, T., and Mizutani, J., Decarboxylative conversion of hydroxycinnamic acids by Klebsiella oxytoca and Erwinia uredovora, epiphytic bacteria of Polymnia sonchifolia leaf, possibly associated with formation of microflora on the damaged leaves. Biosci. Biotechnol. Biochem., 57, 215-219 (1993).

4) Hashidoko, Y., Urashima, M., and Mizutani, J., Cloning of a DNA fragment carrying the 4-hydroxycinnamate decarboxylase (Pof $\mathrm{K})$ gene from Klebsiella oxytoca, and its constitutive expression in Escherichia coli JM109 cells. Biosci. Biotechnol. Biochem., 58, 217-218 (1994).

5) Zago, A., Degrassi, G., and Bruschi, C. V., Cloning, sequencing, and expression in Escherichia coli of the Bacillus pumilus gene for ferulic acid decarboxylase. Appl. Environ. Microbiol., 61, 4484-4486 (1995).

6) Cavin, J.-F., Barthelmebs, L., and Divies, C., Molecular characterization of an inducible $p$-coumaric acid decarboxylase from Lactobacillus plantarum: gene cloning, transcriptional analysis, overexpression in Escherichia coli, purification, and characterization. Appl. Environ. Microbiol., 63, 1939-1944 (1997).

7) Cavin, J.-F., Dartois, V., and Divies, C., Gene cloning, transcriptional analysis, purification, and characterization of phenolic acid decarboxylase from Bacillus subtilis. Appl. Environ. Microbiol., 64, 1466-1471 (1998).

8) Barthelmebs, L., Lecomte, B., Divies, C., and Cavin, J.-F., Inducible metabolism of phenolic acids in Pediococcus pentosaceus is encoded by an autoregulated operon which involves a new class of negative transcriptional regulator. J. Bacteriol., 182, 6724-6731 (2000).

9) Overhage, J., Prieffert, H., and Steinbuchel, A., Biochemical and genetic analyses of ferulic acid catabolism in Pseudomonas sp. strain HR199. Appl. Environ. Microbiol., 65, 4837-4847 (1999).

10) Hashidoko, Y., Tanaka, T., and Tahara, S., Induction of 4-hydroxycinnamate decarboxylase in Klebsiella oxytoca cells exposed to substrate and non-substrate 4hydroxycinnamate analogs. Biosci. Biotechnol. Biochem., 65, 2604-2612 (2001).

11) Heidelberg, J. F., Eisen, J. A., Nelson, W. C., Clayton, R.
A., Gwinn, M. L., Dodson, R. J., Haft, D. H., Hickey, E. K., Peterson, J. D., Umayam, L., Gill, S. R., Nelson, K. E., Read, T. D., Tettelin, H., Richardson, D., Ermolaeva, M. D., Vamathevan, J., Bass, S., Qin, H., Dragoi, I., Sellers, P., McDonald, L., Utterback, T., Fleishmann, R. D., Nierman, W. C., White, O., Salzberg, S. L., Smith, H. O., Colwell, R. R., Mekalanos, J. J., Venter, J. C., and Fraser, C. M., NA sequence of both chromosomes of the cholera pathogen Vibrio cholerae. Nature, 406, 477-483 (2000).

12) Bell, K. S., Sebaihia, M., Pritchard, L., Holden, M. T. G., Hyman, L. J., Holeva, M. C., Thomson, N. R., Bentley, S. D. L., Churcher, J. C., Mungall, K., Atkin, R., Bason, N., Brooks, K., Chillingworth, T., Clark, K., Doggett, J., Fraser, A., Hance, Z., Hauser, H., Jagels, K., Moule, S., Norbertczak, H., Ormond, D., Price, C., Quail, M. A., Sanders, M., Walker, D., Whitehead, S., Salmond, G. P. C., Birch, P. R. J., Parkhill, J., and Toth, I. K., Genome sequence of the enterobacterial phytopathogen Erwinia carotovora subsp. atroseptica and characterization of virulence factors. Proc. Nat. Acad. Sci. USA, 101, 11105-11110 (2004).

13) Hashidoko, Y., and Tahara, S., Stereochemically specific proton transfer in decarboxylation of 4-hydroxycinnamic acids by 4-hydroxycinnamate decarboxylase from Klebsiella oxytoca. Arch. Biochem. Biophys., 359, 225-230 (1998).

14) Asante, A., Tahara, S., and Hashidoko, Y., Screening of rhizobacteria possessing phenolic acid-decarboxylation abilities from several plant families. J. Res. Fac. Agric. Hokkaido Univ., accepted (2008).

15) Hashidoko, Y., Itoh, E., Yokota, K., Yoshida, T., and Tahara, S., Characterization of five phyllosphere bacteria isolated from Rosa rugosa leaves, and their phenotypic and metabolic properties. Biosci. Biotechnol. Biochem., 66, 2474-2478 (2002).

16) Cavin, J.-F., Barthelmebs, L., Guzzo, J., Van Beeumen, J., Bart, S., Travers, J. F., and Divies, C., Purification and characterization of an inducible $p$-coumaric acid decarboxylase from Lactobacillus plantarum. FEMS Microbiol. Lett., 147, 291-295 (1997).

17) Huang, Z., Dostal, L., and Rosazza, J. P. N., Purification and characterization of a ferulic acid decarboxylase from Pseudomonas fluorescens. J. Bacteriol., 176, 5912-5918 (1994).

18) Zdobnov, E. M., and Apweiler, R., InterProScan: an integration platform for the signature-recognition methods in InterPro. Bioinformatics, 17, 847-848 (2001).

19) Barthelmebs, L., Divies, C., and Cavin, J.-F. O., Expression in Escherichia coli of native and chimeric phenolic acid decarboxylases with modified enzymatic activities and method for screening recombinant $E$. coli strains expressing these enzymes. Appl. Environ. Microbiol., 67, 1063-1069 (2001).

20) Li, L., Bannantine, J. P., Zhang, Q., Amonsin, A., May, B. J., Alt, D., Banerji, N., Kanjilal, S., and Kapur, V., The complete genome sequence of Mycobacterium avium subspecies paratuberculosis. Proc. Natl. Acad. Sci. USA, 102, 12344-12349 (2005).

21) Hashidoko, Y., Urashima, M., and Yoshida, T., Predominant epiphytic bacteria on damaged Polymnia sonchifolia leaves, and their metabolic properties on phenolics of plant origin. Biosci. Biotechnol. Biochem., 58, 1894- 
1896 (1994)

22) Clausen, M., Lamb, C. J., Megnet, R., and Doerner, P. W., PADl encodes phenylacrylic acid decarboxylase which confers resistance to cinnamic acid in Saccharomyces cerevisiae. Gene, 142, 107-112 (1994).

23) Edlin, D. A. N., Narbad, A., Gasson, M. J., Dickinson, J. R., and Lloyd, D., Purification and characterization of hydroxycinnamate decarboxylase from Brettanomyces anomalus. Enzyme Microbiol. Technol., 22, 232-239 (1998).

24) Rangarajan, E. S., Li, Y., Innuzzi, P., Tocilj, A., Hung, L.-W., Matte, A., and Cygler, M., Crystal structure of a dodecameric FMN-dependent UbiX-like decarboxylase (Pad1) from Escherichia coli O157:H7. Protein Sci., 13, 3006-3016 (2004). 